American Journal of Environmental Sciences 7 (2): 102-107, 2011

ISSN $1553-345 \mathrm{X}$

(C) 2010 Science Publications

\title{
River Embankment and Bank Failure: A Study on Geotechnical Characteristics and Stability Analysis
}

\author{
Md. Bellal Hossain, Toshinori Sakai and Md. Zakaria Hossain \\ Department of Environmental Science and Technology, \\ Graduate School of Bioresources, Mie University, 514-8507, \\ Tsu shi, Kurimamachiyacho 1577, Mie, Japan
}

\begin{abstract}
Problem statement: Embankment failure and riverbank erosion are common problem in Bangladesh. Almost every year earthen embankments and riverbanks are facing problems like erosion, breaching or retirements. Among many reasons the major causes are considered due to the use of geotechnically unstable materials, improper method of construction, seepage and sliding. In this study the problem is considered geotechnical point of view where the geotechnical properties of failed Jamuna river embankment material and Padma riverbank material were investigated. Moreover, stability analysis technique of embankment has been reviewed through a case study of Manu river embankement. Approach: Sample materials were collected during field investigation and tested at laboratory according to Japanese Industrial Standard (JIS). Limit equilibrium stability analysis and steady state seepage analysis was conducted for Manu river embankment to review the existing design procedure of embankment. Results: Study results reveal that the soil of Jamuna river embankment is not well graded sand and the permeability is found minimum of $1.29 \times 10-5 \mathrm{~cm} \mathrm{sec}^{-1}$ (at $\mathrm{w}=24 \%$ ) which increases rapidly in submerge condition. The maximum strength is found $51.8 \mathrm{kN} \mathrm{m}^{-2}$ which is not preferable as embankment material. Moreover, the slope is not well protected that makes the embankment vulnerable to erosion. In contrast, the soil of Padma riverbank contains mostly sand with $25 \%$ clay content. Both permeability and strength of bank material decrease rapidly with the increase of water content. Nevertheless, tension crack and toe erosion also accelerate the mass failure mechanism of riverbank. From case study the Factor of Safety (FS) is found overestimated of about $22-24 \%$ in stability analysis of embankment in usual practice. Conclusion: Embankment soil needs to be improved geotechnically to minimize mass failure. Geo-bags, cement composites with reinforcement could be used for slope protection. To obtain reliable factor of safety seepage analysis is recommended in designing stable embankment.
\end{abstract}

Key words: Embankment material, riverbank failure, geotechnical properties, seepage analysis, stability analysis, Japanese Industrial Standard (JIS), Factor of Safety (FS), Finite Element Method (FEM), embankment failure

\section{INTRODUCTION}

Earthen embankments in Bangladesh are beset with multi-facetted problems. Devastating flood and excessive rainfall are accelerating the failure process which results immense damage to agriculture and infrastructures every year. Over the last few decades, nearly $13000 \mathrm{~km}$ of flood and river embankments have been repaired in Bangladesh. But, earthen embankments in Bangladesh are facing problems like erosion, breaching in every year. The major causes of failure identified were breach of the embankment, cutting by the public, overflow, erosion, seepage and sliding. Furthermore, insufficient supervision during construction results in poor-quality earthworks with the use of inappropriate soil materials, insufficient or no clod breaking, inadequate compaction and or no insufficient laying of topsoil layers, the use of inferior materials, inadequate maintenance, river migration and cutting by the public (Hoque and Siddique, 1995). Among many reasons, the improper design methodology and construction procedure is prime and one of the most important causes of embankment failure. The stability of earthen embankments is

Corresponding Author: Md. Bellal Hossain, Department of Environmental Science and Technology, Graduate School of Bioresources, Mie University, 514-8507 Tsu shi, Kurimamachiyacho 1577, Mie, Japan

Tel: +81592319578 Fax: +81592319591 
Am. J. Environ. Sci., 7 (2): 102-107, 2011

influenced by seepage occurred during the increase and decrease of the adjacent water level in the river or reservoir (Morii and Kunio, 1993). However, clear understanding of material behavior is necessary to interpret the failure phenomenon of a particular problem. To acquire appropriate understanding, some researchers already tried to characterize geotechnical properties of soil facing mass failure problem like landslides or containing organic matters (Ahmad et al., 2006; Huat et al., 2009). In this study, embankment failure and riverbank erosion problems in Bangladesh have been looked with respect to the factors regarding stability and geotechnical characteristics. Briefly, this study aimed (i) To investigate the physical and mechanical properties of the embankment material of Jamuna river located at Sirajganj district of Bangladesh, (ii) To determine the geotechnical properties of Padma riverbank material and clarify the bank-failure mechanism in Charghat area located in Rajshahi district of Bangladesh, (iii) To evaluate the existing design methodology for embankment stability analysis through a case study.

\section{MATERIALS AND METHODS}

The soil samples were collected from the broken part of the right bank embankment of Jamuna river (Fig. 1) in Shirajganj district and from the eroded bank of Padma River located in Rajshahi district. The laboratory tests were conducted in the Laboratory of Mie University. The testing procedures were in accordance with Japanese Industrial Standard (JIS) and Japanese Geotechnical Standard (JGS). The tests include particle size analysis (JIS A 1204), particledensity (JIS A 1202), liquid limit and plastic limit (JIS A1205), compaction characteristics (JIS A 1210), consolidation, permeability (JIS A 1218), direct shear test (JGS 0560 and 0561) and unconfined compressive strength tests (JIS A 1216). On the basis of the test results, the soil was also classified by JGS engineering classification. The falling head method was followed to determine the coefficient of permeability. The unconfined compressive strength test was done with samples having different water content.

Physical properties: The parameters of basic physical properties are shown in Table 1. The significant difference is found between the plastic and liquid limits of soils. Plastic limit of embankment soil refers to non plastic (NP) where that of riverbank soil is $27 \%$. From grain size distribution analysis, maximum grain size and effective size (D10) of embankment soil were 425 and $7.6 \mu \mathrm{m}$ respectively (Fig. 2).
Table 1: Physical properties of soils

\begin{tabular}{lll}
\hline Properties & Embankment soil & Riverbank soil \\
\hline Particle density & $2.747 \mathrm{~g} \mathrm{~cm}^{-3}$ & $2.676 \mathrm{~g} \mathrm{~cm}^{-3}$ \\
Liquid limit & $25.8 \%$ & $32 \%$ \\
Plastic limit & $\mathrm{NP}$ & $27 \%$ \\
Maximum size & $425 \mu \mathrm{m}$ & $850 \mu \mathrm{m}$ \\
Sand $(75 \mu \mathrm{m}-2 \mathrm{~mm})$ & $51 \%$ & $6 \%$ \\
Silt $(5-75 \mu \mathrm{m})$ & $41 \%$ & $69 \%$ \\
Clay $(<5 \mu \mathrm{m})$ & $8 \%$ & $25 \%$ \\
Soil type & $\mathrm{SF}$ & ML \\
\hline
\end{tabular}

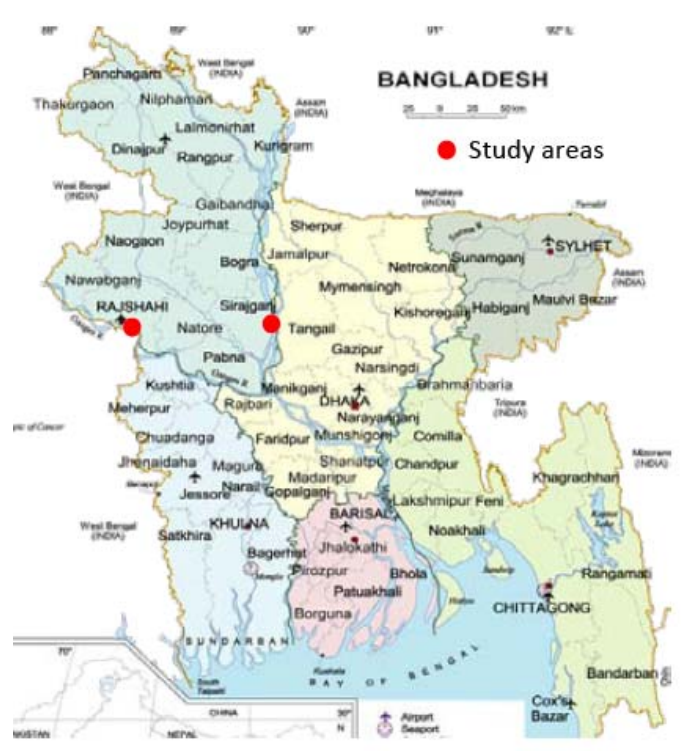

Fig. 1: Study Areas

The fine grain $(<75 \mu \mathrm{m})$ content in embankment soil is found $49 \%$ (silt $=41 \%$, clay $=8 \%)$ and the coarse grain $(\geqq 75 \mu \mathrm{m})$ is $51 \%$. Accordingly, the soil has been classified into SF (Fine sand) group using JGS engineering classification. Similarly, the riverbank soil was classified as silty soil with lower liquid limit (ML) which contents silt and clay of $69 \%$ and $25 \%$, respectively.

Geotechnical properties: From compaction tests result, the maximum dry densities of embankment soil (ES) and Riverbank Soil (RS) are found $1.59 \mathrm{~g} / \mathrm{cm} 3$ and $1.72 \mathrm{gm} / \mathrm{cm} 3$ at optimum water content (wopt) of $21.2 \%$ and $16.5 \%$, respectively (Fig. 3 ). The changes in permeability and strength values of ES with the increase of water content are plotted in Fig. 4. The minimum value of permeability coefficient is calculated as $1.29 \times 10-5 \mathrm{~cm} / \mathrm{s}$ at $24 \%$ water content which is beyond the optimum water content and near to liquid limit $(\mathrm{w}=25.8 \%)$. The change in the coefficient of permeability was observed almost one order larger value from the smallest coefficient of permeability for unit change of water content on dry side. 
Am. J. Environ. Sci., 7 (2): 102-107, 2011

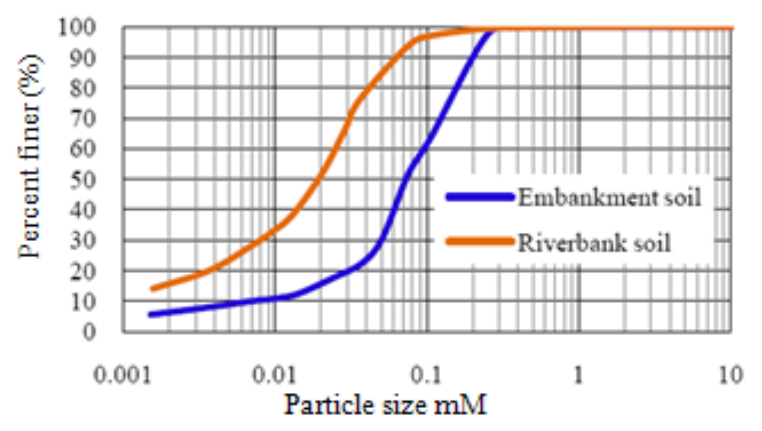

Fig. 2: Particle size distribution curves

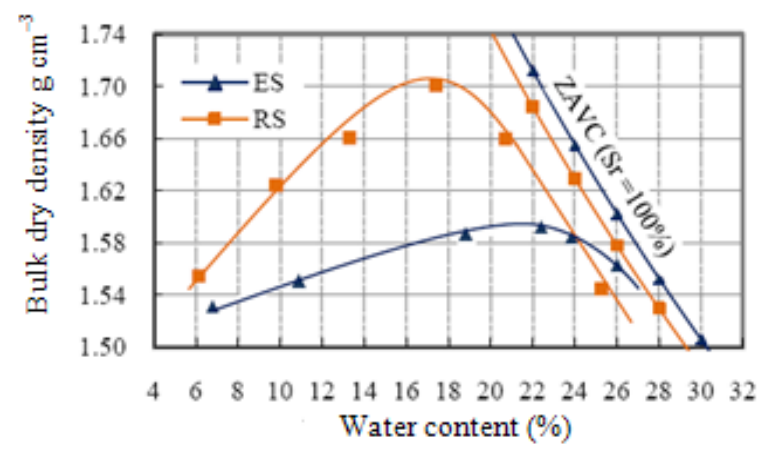

Fig. 3: Compaction curves of ES and RS

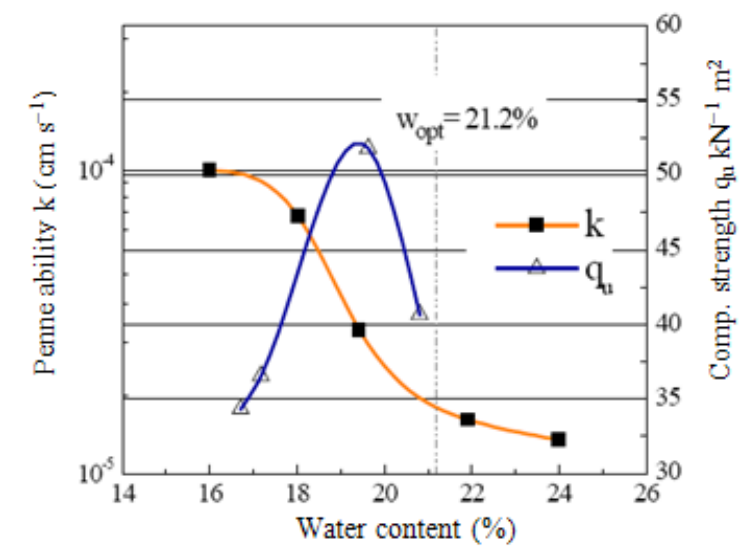

Fig. 4: Permeability and strength of embankment soil with water content

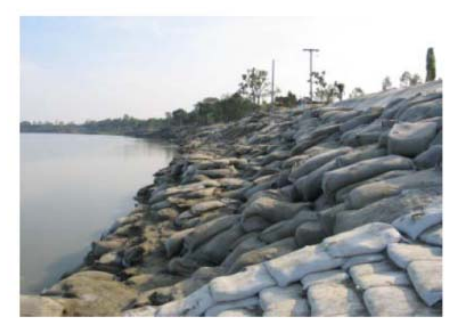

Fig. 5: Sandbags on embankment slope

\section{RESULTS AND DISCUSSION}

It is also predicted that the permeability is increased rapidly in submerge condition of the soil. From uniaxial compression test, the maximum value of compressive strength (qu) was reported as $51.8 \mathrm{kPa}$ at $19.6 \%$ water content which is below the optimum water level. It was also clear that the uniaxial compressive strength of the soil largely varied with the small change in water content.

So, the embankment constructed with this material needs lot of care to control water content and the strength level. As embankment material; it has got a very low strength and thus, very vulnerable to slope failure and erosion process. Hence, the slope surface needs to be protected from erosion caused by the rainfall, run off and the strong wave during high flow of river. However, the slope of the embankment of Jamuna river is found not well protected. In some places of the embankment, sandbags have been used but not worked well due to inefficient placement and lack of maintenance (Fig. 5).

Moreover, the sandbags are placed only in the emergency situation of flood. But, it is equally important to protect the slope surface during other times to protect from wash-off the fine particles by rainfall as well as run off. Some other places, precast concrete blocks are being used as a riprap. But, these are very expensive and so it is limited to some extent only. Bangladesh doesn't have large abundant quantities of rock. Sand is the cheapest and only readily accessible material throughout the construction season. So, the sandbag application could be the practical way of protecting embankment dam in Bangladesh. Besides sandbag; thin layer of cement composites can be used as a measure of slope protection. But, a comprehensive study of its impact on the slope stability condition is required to find out an effective and sustainable system of slope protection.

The effect of water content on the geotechnical properties of riverbank soil is shown Fig. 6. The value of permeability is found to be $3.5 \times 10-7 \mathrm{~cm} / \mathrm{s}$ at over $90 \%$ saturation. From direct shear test, the shear strength parameters, cohesion (c) and internal frictional angle (ø) were obtained as $153 \mathrm{kPa}$ and $22^{\circ}$, respectively.

The maximum compressive strength was found to be $280 \mathrm{kPa}$ at $12.8 \%$ water content which is below the optimum water content (16.45\%). But, the strength decreases rapidly with the increase of water content and reaches to about $150 \mathrm{kPa}$ at $22 \%$ water content. It is also observed that the strength reduces $46 \%$ with the increase of water content by $10 \%$ after the peak value. 


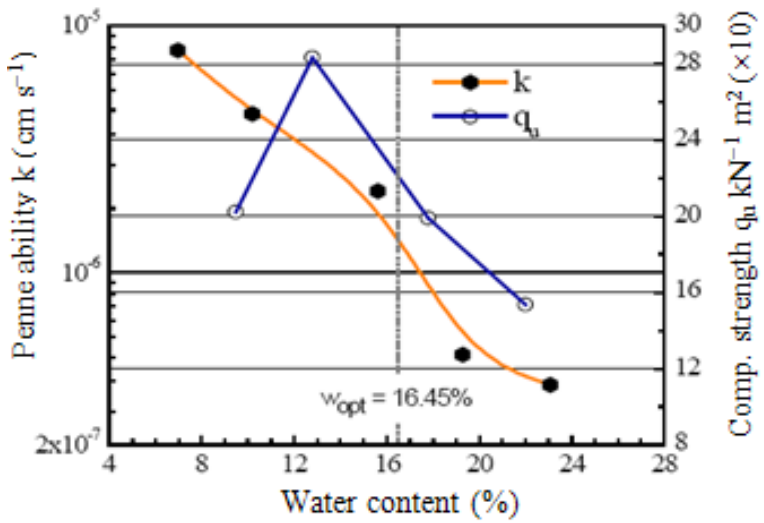

Fig. 6: Change of strength and permeability with water content of riverbank soil

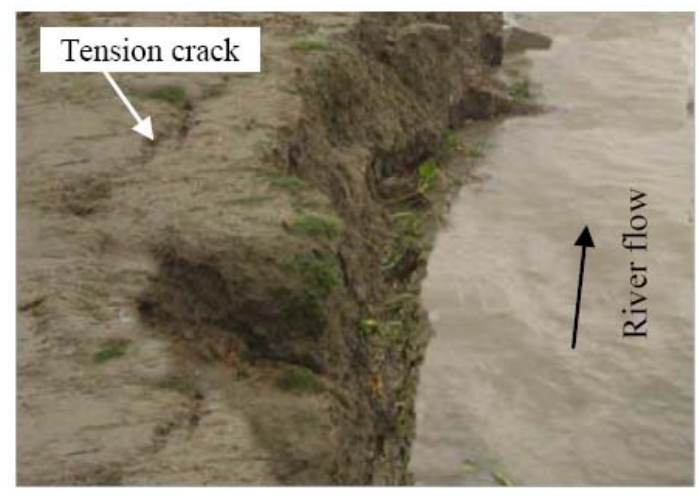

Fig. 7: Riverbank failure at charghat

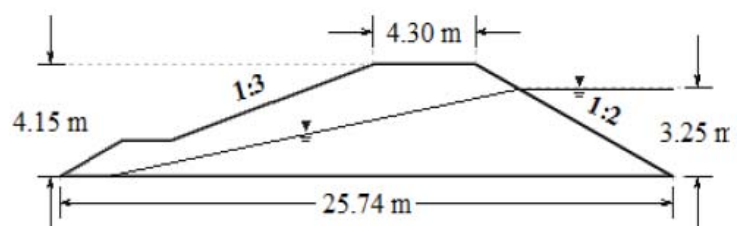

Fig. 8: Section of Manu river embankment

Bank failure mechanism: The bank-failure mechanism of Padma river in the study area was identified based on the field observations, discussion with the local community and the test results of the sample materials. The failure is associated with the formation of tension cracks few feet behind the bank line (Fig. 7). It is also reported that the severe bank failure occurs during the recession of flood water when the velocity of river flow seems to be very high. This type of failure can be described as slab-type rotational failure that includes both mechanisms such as planar failure with tension crack and toppling involving failing blocks with the same geometry. From geotechnical point of view, it is understood that the strength of bank soil decreases rapidly with the increase of water content. The permeability also becomes very low $(<1 \times 10-6 \mathrm{~cm} / \mathrm{s})$ at the same time (Fig. 6) which ultimately increases the weight of material and triggers mass failure of bank.

In addition, during drawdown of river water at the end of flood, groundwater level in the bank decreases at a lower rate than the level of surface water due to low permeability of the bank material. This phenomenon causes an imbalance of force of water pressure in the riverbank and the confining pressure of surface water on the slope which also causes sudden mass failure of the bank. In this circumstance, it is very much necessary to find out the limiting value of the critical bank slope and height in order to take necessary measure for the protection of riverbank in the study area. A limit equilibrium method of bank stability analysis can be followed as proposed by Darby and Thorne (1996). This is a new approach for riverbank stability analysis which can be applicable for the steep, cohesive, non-layered riverbank that fails along planar failure surface. In this method, pore-water and hydrostatic confining pressure are also included where the failure plane is not constrained to pass through the toe of the bank.

Case study: A case study was conducted on the Manu river embankment which is located in Moulvibazar district of Bangladesh. The embankment was designed (Fig. 8) considering the free surface in embankment as an assumed saturation line which is decided on soil type according to design manual of Bangladesh Water Development Board (BWDB). In this study, the free surface is reasonably determined by conducting seepage analysis using Finite Element Method (FEM). The slope stability analysis was performed by limit equilibrium methods and the results were compared with the existing values.

Hydraulic functions and seepage analysis: The hydraulic model for seepage analysis was the Genuchten (1980) model which is the most widely used model in simulation of unsaturated flow processes. Therefore, it has been used in this study for representing the relationship between the hydraulic conductivity and the pressure head as shown in (1):

$\mathrm{k}_{\mathrm{h}}=\mathrm{k}_{\mathrm{s}} \sqrt{\mathrm{S}_{\mathrm{e}}}\left\{1-\left[1-\mathrm{S}_{\mathrm{e}}^{(\mathrm{n} / \mathrm{n}-1)}\right]^{1-1 / \mathrm{n}}\right\}^{2}$ 
Am. J. Environ. Sci., 7 (2): 102-107, 2011

Table 2: Summary of FEM seepage analysis

\begin{tabular}{lcccc}
\hline & $\begin{array}{l}\text { Node } \\
\text { (Nos) }\end{array}$ & $\begin{array}{l}\text { Element } \\
(\text { Nos })\end{array}$ & $\begin{array}{l}\text { Flow at } \\
\text { mid section, } \\
(\times 10-8 \mathrm{~m} \\
\left(\mathrm{sec}^{-1}\right)\end{array}$ & $\begin{array}{l}\text { Deviation } \\
(\%)\end{array}$ \\
Element type & & & 9.499 & 0.110 \\
\hline Triangular & 551 & 990 & 9.514 & 0.270 \\
Triangular & 786 & 1436 & 9.480 & 0.086 \\
Quadrilateral & 528 & 474 & 9.460 & 0.297 \\
Quadrilateral & 983 & 908 & & \\
\hline
\end{tabular}

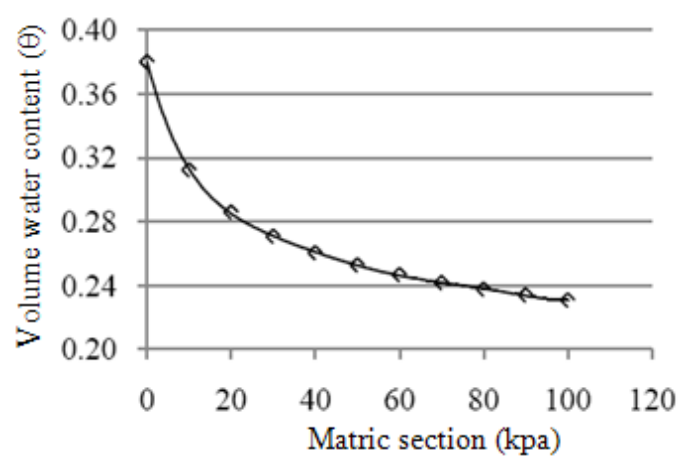

Fig. 9: Water-retention curve

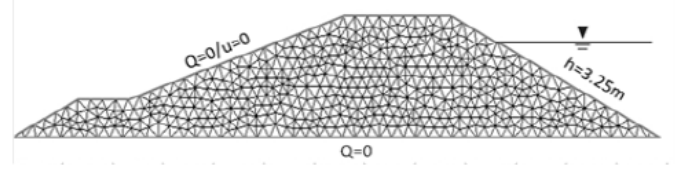

Fig. 10: Finite element mesh and boundary condition

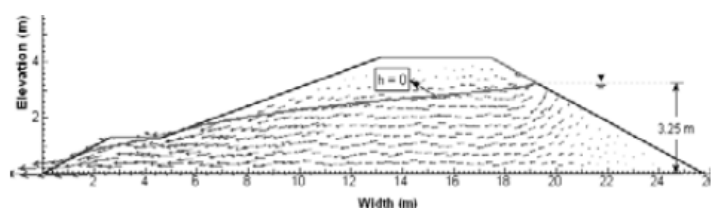

Fig. 11: Seepage through embankment

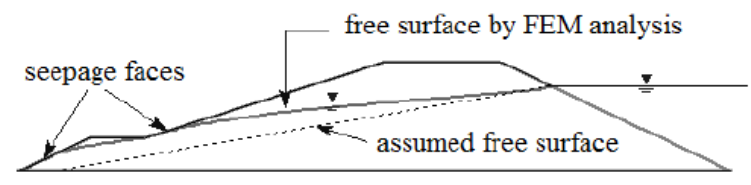

Fig. 12: Location of free surface and seepage face

where, kh is the coefficient of permeability at any pressure head $h, k s$ is the saturated coefficient of permeability:

$$
\mathrm{S}_{\mathrm{e}}=\left[\frac{1}{1+(\mathrm{ah})^{\mathrm{n}}}\right]^{\mathrm{m}}
$$

$\mathrm{m}=1-\frac{1}{\mathrm{n}}$

$\mathrm{h}=$ Soil-water pressure head in meter $\alpha(1 / \mathrm{m})$

$\mathrm{n}=$ Curve shape parameters

These hydraulic parameters (ks, $\alpha$ and n) were predicted by using a database program ROSETTA (Schaap et al., 2001) that used soil texture data for predicting the parameter values. The soil type of Manu river embankment is sandy-clay for which the hydraulic parameters $k s, \alpha$ and $\mathrm{n}$ were predicted as $3.33 \times 10-7 \mathrm{~m} / \mathrm{s}$, 2.7 and 1.23 respectively. Using these hydraulic parameters the soil-water retension curve is plotted as shown in Fig. 9.

The boundary conditions and hydraulic properties were same for all types of elements in FEM seepage analysis. The domain was discretized using both quadrilateral and triangular elements. Four trials were done with different type of elements and numbers to compare the variation of free surface position. First two analyses were done considering 3 noded triangular elements and other two were considered with four noded quadrilateral elements. Boundary conditions of the domain for each analysis were set as shown in Fig. 10. Moreover, total flux at the middle of the section was calculated for various discretized domain for comparison purpose. A summary of seepage analysis are also given in Table 2 .

The coefficient of permeability function does not need to be specified precisely when computing the distribution of pore-water pressure. Therefore, an approximate permeability function is adequate for analysis purposes (Thieu et al., 2001). The quantity of flux through the mid section is slightly different, as shown in Table 2. The deviation shown is not significant and the result would indicate that the position of free surface is almost same for any type and any numbers of elements. Figure 11-12 represent the results of seepage analysis.

Slope stability analysis: Stability of the Manu river embankment was checked in terms of Factor of Safety (FS) values. Followed by FEM seepage analysis, limit equilibrium slope stability analysis was conducted both for assumed saturation line (1:5.45) and free surface predicted by FEM seepage analysis. The saturated and unsaturated unit weight of soil was taken as $120 \mathrm{pcf}$ $\left(18.8 \mathrm{KN} \mathrm{m}^{-3}\right)$ and $115 \mathrm{pcf}\left(18.1 \mathrm{KN} \mathrm{m}^{-3}\right)$, respectively. The Mohr-Coulomb strength criterion was used with the shear strength parameters of cohesion, $\mathrm{c}=100 \mathrm{psf}$ $(4.78 \mathrm{kPa})$ and friction angle, $\varphi=18^{\circ}$. Random technique for generating circular surfaces has been used to find a critical failure surface from 100 trial surfaces. 
Am. J. Environ. Sci., 7 (2): 102-107, 2011

Table 3: Results of slope stability analysis

\begin{tabular}{|c|c|c|c|}
\hline \multirow[b]{2}{*}{ Methods } & \multicolumn{3}{|c|}{ Minimum factor of safety (FS) } \\
\hline & $\begin{array}{l}\text { Assumed } \\
\text { saturation line }\end{array}$ & $\begin{array}{l}\text { Predicted } \\
\text { free surface }\end{array}$ & $\begin{array}{l}\text { Deviation } \\
(\%)\end{array}$ \\
\hline Bishop simplified & 2.011 & 1.622 & 23.98 \\
\hline Janbu simplified & 1.880 & 1.541 & 21.99 \\
\hline Spencer & 2.012 & 1.622 & 24.04 \\
\hline Crop of eng\#1 & 2.043 & 1.648 & 23.96 \\
\hline Morganstern-price & 2.011 & 1.622 & 23.98 \\
\hline
\end{tabular}

The lower and upper angle limit of each failure surface at toe was set as $-5^{\circ}$ and $-45^{\circ}$, respectively (-ve for anticlockwise direction). Table 3 shows the summary of limit equilibrium analysis.

The results show that the factor of safety is over estimated about $22-24 \%$ in case of assumed saturation line. Moreover, the assumed saturation line does not satisfy the Laplace equation for two-dimensional flow through a homogeneous, isotropic medium. Hence, seepage analysis is necessary to solve the seepage problem as well as to get the reliable factor of safety value and safe design of embankment.

\section{CONCLUSION}

The following conclusions can be drawn from the present study:

- The soil which was used for constructing Jamuna river embankment has been found poorly graded sand with higher silt content. The permeability of the soil is high with the lower strength properties. There is no protective measure on the slope and easy to be washed off by rain and wave action

- In contrast, the Padma riverbank soil contains mostly the silt particles with $25 \%$ of clay content. Excessive pore water pressure affects the shear strength of bank material which leads to the mass failure of the bank

- In the study area, bank failure mechanism is associated with the formation of tension crack

- behind the bank face. The type of failure is categorized as slab-type rotational failure mechanism

- In slope stability analysis of embankment, the factor of safety is found to be overestimated for assumed saturation line

Recommendations: The geotechnical properties of embankment material need to be improved by using additives or reinforcing materials like soil-cement, natural or geosynthetic fiber etc. It is also necessary to protect the slope by facing materials using geo-bags, cement composites with reinforcement etc. It is also recommended to locate the free surface inside the embankment by conducting seepage analysis prior to conduct slope stability analysis to obtain more reliable factor of safety in designing stable embankment.

\section{ACKNOWLEDGEMENT}

The preliminary version of this study was presented at the "International Conference on Environmental Aspects of Bangladesh (ICEAB10) [RW5]"

\section{REFERENCES}

Ahmad, F., A.S. Yahaya and M.A. Farooqi, 2006. Characterization and geotechnical properties of penang residual soils with emphasis on landslides. Am. J. Environ. Sci., 2: 121-128. DOI: 10.3844/ajessp.2006.121.128

Darby, S.E. and C.R. Thorne, 1996. Development and testing of riverbank-stability analysis. J. Hyd. Eng., 122: 443-454. DOI: 10.1061/(ASCE)07339429(1996)122:8(443)

Hoque, M.M. and M.A.B Siddique, 1995. Flood control projects in Bangladesh: Reasons for failure and recommendations for improvement. Disasters, 19: 260-263. DOI: $\quad 10.1111 /$ j.14677717.1995.tb00344.x

Huat, B.B.K., A. Asadi and S. Kazemian, 2009. Experimental investigation on geomechanical properties of tropical organic soils and peat. Am. J. Eng. Applied Sci., 2: 184-188. DOI: 10.3844/ajeassp.2009.184.188

Morii, T. and H. Kunio, 1993. Finite element analysis of stress and stability of earth dams during reservoir filling. J. Fac. Agric., Tottori Univ., 29: 45-53.

Schaap, M.G., F.J. Leij and M.T. Van Genuchten, 2001. ROSETTA: A computer program for estimating soil hydraulic parameters with hierarchical pedotransfer functions. J. Hydrol., 251: 163-176. DOI: 10.1016/S0022-1694(01)00466-8

Thieu, N.T.M., M.D. Fredlund and V.Q. Hung, 2001. Seepage modeling in a saturated/unsaturated soil system. Proceedings of the International conference on management of the Land and Water Resources, Oct. 20-22, Hanoi, Vietnam, pp: 1-8.

Van Genuchten, M.T., 1980. A closed-form equation for predicting the hydraulic conductivity of unsaturated soils. Soil Sci. Soc. Am. J., 44: 892898.

DOI: 10.2136/sssaj1980.03615995004400050002x 